Escuela de Ciencias Sociales y Humanidades, UNED, C.R.

URL: http://investiga.uned.ac.cr/revistas/index.php/espiga/index

ISSN: 1409-4002 • e-ISSN: 2215-454X

\title{
Cruzando entre la Gran Muralla china y el «gran» muro de Trump ${ }^{1}$
}

Mimi Yang*

(iD) http://orcid.org/0000-0003-4070-5323

Recibido: 10 de febrero, 2019 - Aceptado: 21 de febrero, 2019

Traducción de Carolina Arias Núñez

\section{RESUMEN}

¿Puede un muro fronterizo realmente disuadir tanto a invasores como a quienes lo cruzan, a la vez que defender, unificar y mantener la «pureza» de la cultura que encierra? El primer emperador chino Qin Shihuang (259-210 a.C.) y sus sucesores en las siguientes dinastías trataron de lograr ese propósito; la Gran Muralla china testimonia eternamente tales esfuerzos épicos. ¿Tuvieron éxito los gobernantes chinos? La pregunta se ha vuelto cada vez más desalentadora e incontestable a medida que la historia se desarrolla y evoluciona. Irónicamente, durante más de dos milenios, la construcción fragmentaria de la Gran Muralla secuenció un «ADN-del-muro»

\section{Formato de citación según APA}

Yang, M. (2019). Cruzando entre la Gran Muralla china y el «gran» muro de Trump. Revista Espiga, 18 (37), 1-13.

\section{Formato de citación según Chicago-Deusto}

Yang, Mimi. (2019). «Cruzando entre la Gran Muralla china y el "gran” muro de Trump». Revista Espiga 18, n. 37 (enero-junio, 2019): 1-13.

* Doctora en Lengua y Literatura Española por la Universidad de Arizona. Catedrática de Lenguas Modernas en Carthage College, Wisconsin, EE. UU. Autora del libro The Tricultural Personality (Chinese, Hispanic, English): A Paradigm for Connecting Culture Differences (Edwin Mellen, 2014). Autora de numerosos artículos sobre diferentes aspectos de la literatura y la cultura latinoamericanas. Autora de una variedad de publicaciones sobre temas estadounidenses. En 2004, le fue otorgado el Wisconsin Global Educator Award at Higher Education Level. Correo: myang@carthage.edu

1. Este artículo fue publicado originalmente en inglés por Palgrave Communications. Su versión en inglés, Crossing between the Great Wall of China and the «Great» Trump Wall, puede ser consultada en la siguiente dirección: https://www.nature.com/articles/s41599-017-0031-2. Se traduce bajo acuerdo con la autora, cuya publicación fue aceptada por el Comité Editorial de la Revista Espiga debido a la calidad del contenido y a la coyuntura actual en relación con el tema desarrollado. 
que ha quedado grabado como huella cultural. En el rápido avance hacia los Estados Unidos (EE. UU.) del siglo XXI, se plantean las mismas preguntas cuando el presidente Trump promete construir un muro «grande, grande», físico e impenetrable, en la frontera entre EE. UU. y México. El muro de Trump ha sido diseñado para detener a los inmigrantes ilegales mexicanos que ingresan a EE. UU., con el fin de proteger los intereses de los estadounidenses, que el idioma inglés no sea «contaminado» y sus valores no sean cuestionados. El muro de Trump se establece para delinear lo que son los EE. UU. y, por lo tanto, intenta «hacer que EE. UU. vuelva a ser grande». Bajo un compromiso intercultural, este artículo decodifica el «ADN-del-muro» en la cultura estadounidense, argumenta que el muro de Trump es un constructo más mental que físico e invita a redefinir la identidad cultural estadounidense del siglo XXI frente a dicho muro.

Palabras clave: Muro de Trump, Gran Muralla China, frontera, México, inmigración.

\section{Introducción}

¿Puede un muro fronterizo realmente disuadir tanto a invasores como a quienes lo cruzan, a la vez que defender, unificar y mantener la «pureza» de la cultura que encierra? En la historia humana, a través de las culturas se han construido innumerables muros para mapear las fronteras; demarcar una ciudad, estado o imperio y proteger a sus constructores. La Gran Muralla china es quizás el muro fronterizo más grande jamás construido. Los constructores chinos - gobernantes de la Dinastía Qin en el 221 a.C., Ming y sucesivas dinastías- no imaginarían el eco de su visión de mundo y la réplica de sus estructuras arquitectónicas en el $45^{\circ}$ presidente estadounidense, Donald Trump, y en los EE. UU. del siglo XXI. Cuando Trump hizo del «gran, gran» muro en la frontera con México su lema de campaña, la cultura estadounidense fue advertida sobre una mentalidad-de-muro, cerrada y colosal, que evidentemente define a la administración Trump y se ha convertido en un proyecto de muro real en su lista de prioridades.

A lo largo de mil millas en el Pacífico y por un periodo de más de dos milenios, la Gran Muralla china y el «gran» muro de Trump se encuentran en medio del resurgir neonazi, de la supremacía blanca, el sentimiento antiinmigrante, la prohibición musulmana y transgénero, de una ola antisemita y de repercusiones misóginas y sexistas. Ambos, también, se reúnen frente a un eco y una coalición improbables entre afroamericanos, judíos estadounidenses, musulmanes estadounidenses, feministas estadounidenses y muchos otros marginados. El malestar racial en Charlottesville ha revelado claramente que «unir a la derecha» se ha envalentonado gracias a las acciones del presidente Trump y ha sido alimentado por su orden ejecutiva de crear un muro fronterizo entre México y EE. UU., entre otras órdenes ejecutivas para construir más muros invisibles. «Unir a la derecha» levanta un muro cultural que pretende excluir a cualquier individuo o grupo que se perciba como «menos» estadounidense. Frente a un muro y una guerra culturales llenos de intolerancia, el muro fronterizo EE. UU.-México de Trump se convierte en uno que, más que proteger, divide física y psicológicamente a los estadounidenses.

Devolviéndose en el tiempo al 221 a.C., la unificación de China por parte del primer emperador Qin Shihuang (259 a.C -210 a.C.) significó el fin de los caóticos y conflictivos Estados Guerreros y el comienzo de una identidad imperial y cultural coherente. Las murallas y demarcaciones de la ciudad que obstruían e impedían este propósito tenían que 
ser derribadas, redirigidas y conectadas a una gran muralla recién erigida que pretendía rodear y proteger todo el imperio. Así surgió la Gran Muralla china.

Desde el inicio de la historia china, un muro acuerpa una cultura, delinea una mentalidad y define/defiende una identidad colectiva. Un muro es la construcción de una narrativa, un linaje, un patrimonio y una propiedad. La Gran Muralla china se erigió para responder a una necesidad imperial de unidad e identidad y a un propósito dinástico para el patrimonio. De hecho, fue una construcción fragmentada por sucesivos gobernantes chinos a lo largo de sus respectivas dinastías, particularmente en la Dinastía Ming (1368-1644).

A través de una historia que abarca más de 2000 años, mitos y misterios, leyendas e historias, hechos y ficciones se entretejieron y rodearon un muro de más de 13000 millas, del este al oeste chino. A lo largo del sinuoso muro, ascendente y descendente, ramas que se arrastran y vides trepadoras del árbol de la civilización china han brotado de las montañas, se han extendido a los pastizales, han subido a las mesetas y se han hundido profundamente en los desiertos. Un inconfundible ADN cultural de cromosomas chinos ha sido secuenciado y dibujado en esta icónica pared serpentina: es la forma del «ADN-del-muro».

Aquí, surgen las preguntas: ¿Qué ADN cultural fue codificado en la Gran Muralla china? ¿Cómo se escriben estos códigos en el «gran» muro de Trump?

\section{Código 1 almacenado en el ADN-del-muro: nosotros, los civilizados y superiores frente a ellos, los bárbaros e inferiores}

El nombre «la Gran Muralla china» es inapropiado en las lenguas occidentales, aunque es comprensible, dada su longitud y magnitud. En chino, en realidad, se llama «la ciudad larga»-Chang Cheng (长城). «Chang» significa largo y «Cheng», ciudad o estado.

De hecho, «China» es otro nombre sumamente inapropiado en el mundo occidental. El país se llama Zhong Guo (中国) que significa el «Reino Medio», en idioma chino.

Aunque el nombre propio «Zhong Guo» o «Reino Medio»" no ingresó al idioma chino hasta después de la caída de la última dinastía, la gran Qing, en 1912, la sensación de ser el punto focal entre los reinos vecinos y el centro del mundo había sido consistente a lo largo de su historia. No hace falta decir que la Gran Muralla y el sentido de un «Reino Medio» siempre han interactuado como parte de una simbiosis cultural. Al igual que en muchas civilizaciones, en la antigua China, las ciudades y los estados eran amurallados con torres de vigilancia, trincheras y fortalezas en la parte superior o intermedia. La Gran Muralla se desarrolló a partir de un sistema anterior de fronteras amuralladas ${ }^{2}$. Una vez que los Estados Guerreros llegaron a su fin en el 221 a.C., las fortificaciones y

1. A lo largo del texto, he usado Zhong Guo (长城) o el Reino Medio retrospectiva y retroactivamente para trazar el constructo mental de Qin Shihuang, el cual ha jugado un papel fundamental en la herencia e identidad de la cultura china durante el siglo XXI.

2. O. Lattimore, Origins of the Great Wall of China: a frontier concept in theory and practice (Geogr Rev, 1937), 529-549. 
murallas entre ellos y alrededor de sus respectivos estados y ciudades fueron desmanteladas o «remodeladas». Algunas fueron alargadas y mejoradas; otras, redirigidas y (re) conectadas. Todo debía servir a un propósito mucho mayor, esto es, rodear el nuevo estado largo y unificado, la «Chang Cheng» (长城), y construir una noción del Reino Medio. Por lo tanto, el nombre «Chang Cheng» o la Gran Muralla, tanto en chino como en lenguas occidentales, está inextricable y quizás genéticamente unido a la formación de un Reino Medio unificado, magnificado y engrandecido, es decir, «Zhong Guo», en chino moderno.

Por el contrario, el Reino Medio, en su significado original, es el núcleo de una civilización ubicada en el corazón y el centro del mundo. Un centro se convierte en tal, solo en relación con la periferia y los marginados. El Reino Medio, con su predominante ascendencia Han, solo puede seguir siendo significativo en una relación perpetua con las periferias, en este caso, los «bárbaros» del norte y pueblos nómadas como Xiongnu, Qian, Li y, más tarde, los mongoles, entre otros. La cosmovisión sinocéntrica separa a los Han civilizados y superiores de los «bárbaros» e «inferiores» del norte. Nosotros somos los justos y verdaderos; ellos, los malos y menos dignos. El paradigma «nosotros frente a ellos» necesita un muro para darle forma y, más importante aún, aferrarse a ello en el curso de la impredecible historia y de la inestable formación de la identidad.

Una vez establecida la línea principal de la Gran Muralla, el concepto de que la frontera debe ser absoluta e inamovible se aplica inmediatamente a la formación cultural ${ }^{3}$. La seguridad y los intereses del Reino Medio no solo deben protegerse y defenderse, sino también acentuarse y glorificarse con un muro poderoso, simétrico, hermoso e indestructible. Desde su fundación, la cultura china fue codificada con un ADN-del-muro que crea y enmarca una mentalidad-del-muro.

El «gran» muro de Trump en curso se encuentra con la Gran Muralla china en la frontera «nosotros frente a ellos» y en la división nosotros/ellos. Hace más de 200 años, la nación fue creada por un grupo de seres humanos menos que perfectos, pero se enfrentaron al poderoso Imperio británico con una visión y valor extraordinarios. Destruyeron el muro que bloqueaba sus derechos inalienables de vida, libertad y búsqueda de la felicidad. Al liberarse y separarse de los británicos, «nosotros», una identidad cultural estadounidense, se hizo posible. Esta es la historia inmortalizada de nuestros Padres Fundadores, los primeros derribadores de muros en esta República. Mientras tanto, irónicamente, también fueron constructores de paredes. Muchos de los Padres Fundadores eran dueños de esclavos y no trataban ni a los negros ni a los indígenas como iguales. Thomas Jefferson escribió la Declaración de Independencia y ayudó a iniciar la Guerra de Independencia, pero luego decidió regresar a su preciada plantación de Monticello donde los esclavos africanos hacían posibles sus derechos de libertad y búsqueda de la felicidad.

El muro entre los Padres Fundadores blancos y los esclavos negros nunca fue derribado, a pesar de la elocuencia y nobleza del ideal democrático. De hecho, este muro invisible, la esclavitud del sur, tenía que mantenerse allí para desarrollar y vitalizar la economía de la nación recién fundada. Desde el comienzo, no muy diferente al Reino 
Medio en China, como nación, EE. UU. también germinó a partir de un ADN-del-muro y una mentalidad-del-muro que derribaba una pared y erigía otra simultáneamente. Esta es una nación formada con la sangre procedente del choque con el muro imperial británico y sostenida con la sangre constantemente generada por choques permanentes con el inaceptable muro racial. Los jugadores a ambos lados del muro cambiaron: primero, los patriotas contra los británicos; luego, los dueños de esclavos contra los esclavos; más tarde, el norte contra el sur y así sucesivamente. Nunca ha habido un solo muro de serpentina que rodee todo el país (todavía no); no obstante, la historia de EE. UU. se ha construido sobre muros deconstruidos incesantemente para defender y proteger siempre a un grupo central y predominante frente a otros, por medio de la discriminación, la intolerancia y la violencia. Alguien tenía/tiene que gobernar y ser el gobernante, no todos.

La era de Trump ya ha sido testigo de una multitud de muros que dividen, dicotomizan y confunden a los estadounidenses y al mundo, porque es necesario proteger los intereses de ciertos grupos, en nombre del patriotismo y el interés nacional, así como en nombre de la cultura estadounidense. El Congreso pasó un proyecto de ley el 27 de julio de 2017 con el fin de aprobar \$1,6 mil millones para el muro en la frontera de EE. UU. y México, también conocido como el Muro de Trump. Este es un muro que conectaría y enrutaría cercas y fortificaciones construidas durante las administraciones de Bush y Obama. Sin embargo, este es también un muro físico que encapsula un muro cultural, un muro racial, un muro económico, un muro psicológico y un muro mental.

El resurgimiento de la supremacía blanca, el nacionalismo blanco, la extrema derecha, los puntos de vista misóginos, la homofobia, la islamofobia y la xenofobia se colocan ladrillo a ladrillo en el Muro de Trump. De este modo, se convierte en una plataforma para que esos elementos culturales se conecten, se unan y se canalicen para «unificar a la derecha». El Muro de Trump se basa en el miedo, el fanatismo y, sobre todo, en una intolerancia fundamental por la diferencia. Un mensaje claro y fuerte está escrito en el muro de que los inmigrantes (legales e ilegales) roban empleos, explotan los servicios públicos y plantean riesgos de seguridad. Bajo la semejanza estructural, el Muro de Trump resuena notablemente con el propósito central de la Gran Muralla china: aquellos que «traspasan la frontera» erosionan nuestra identidad nacional e imperial y contaminan nuestra cultura e idioma; entonces, deben ser detenidos con una pared. Esta es una opinión ampliamente sostenida no solo por muchos individuos conservadores y motivados por el miedo en los EE. UU., sino también en muchos países que reciben inmigrantes.

La presidencia de Trump alimenta el sentimiento antiinmigrante. La mentalidad-delmuro se desarrolla con dos hilos familiares antagonistas: nosotros frente a ellos, haciendo eco a la infraestructura china. En la cultura política estadounidense, las dos líneas están codificadas en el Muro de Trump: nosotros somos la cultura estadounidense y ellos son una cultura alienígena. La era de Trump permite que el «nosotros», es decir, los supremacistas/nacionalistas blancos y los grupos de extrema derecha monopolicen la identidad y la cultura estadounidenses, sin tener en cuenta los reclamos de otros estadounidenses que han sido parte integral en la historia, economía y cultura de la nación. Existe una atmósfera cultural trumpiana para que estos «verdaderos» estadounidenses ejerzan su influencia entre una población masiva de individuos conservadores y temerosos. Incluso los funcionarios públicos y los políticos están atrapados en una dicotomía impulsada por el miedo de lo nacional contra lo extranjero. Como un emperador chino, Trump opera 
la dicotomía para dividir a la sociedad multicultural y multirracial y mantener su base de apoyo entre los «verdaderos» estadounidenses como el centro y el «Reino Medio». El «gran» Muro de Trump se propone defender y proteger el «Reino Medio trumpiano».

La visión de mundo desde el centro y el «Reino Medio» explica la posición de Trump en la disputa racial en Charlottesville. Fue un nuevo recordatorio de que la muralla racial está viva; de hecho, fue un bloque de construcción en el Muro de Trump y giró el reloj hacia atrás. Cuando Trump culpó a «muchos bandos» equiparando a los neonazis con los contramanifestantes y elogiando a «muchas personas buenas» en ambos bandos, dio a entender que hay buenos neonazis y buenos supremacistas blancos. Estos son apologéticamente energizados por el «gran» Muro de Trump. En la profundidad de su conciencia, Trump no puede denunciar explícitamente a los grupos que han sido los más antiamericanos, pero que se consideran a sí mismos como los estadounidenses «verdaderos» y «últimos» que habitan en el «Reino Medio» de la cultura estadounidense. Estos excluyen a todos los demás que tengan un credo o color de piel diferentes a los de la cultura estadounidense del «Reino Medio». Consideran que los afro-estadounidenses, los hispanoestadounidenses, los musulmanes, judíos y asiáticos estadounidenses son, en el mejor de los casos, menos o no-estadounidenses y, en el peor de los casos, terroristas, violadores, delincuentes y malos «hombres». La victoria presidencial de Trump tiene una base de apoyo en estos «verdaderos» estadounidenses, quienes mantienen hasta la fecha, explícita o implícitamente, que los blancos hablantes de inglés, protestantes de ascendencia noreuropea son los dueños de la cultura, los valores y las oportunidades estadounidenses. Muchos de ellos son trabajadores de "cuello azul» (obreros) sin título universitario y que se sienten abandonados por una globalización sin precedentes. No reconocen que el Muro de Trump representa una mentalidad etnocéntrica que apela a los grupos neonazis, a la supremacía blanca y a grupos de extrema derecha en diferentes grados y contextos.

Similar a la mentalidad de Qin Shihuang y de los sucesivos gobernantes chinos, el universo político de Trump gira alrededor de un «Reino Medio» compuesto por el poder, la civilización y la supremacía blancos y, de manera conveniente, alrededor de la blancura de los «Padres Fundadores». En su universo, cualquier grupo con un color de piel, un credo o una religión diferentes no encaja bien con su «Reino Medio». No se puede dejar de recordar el Movimiento Birther que él defendió y perpetuó en contra del primer presidente afroamericano, quien no pertenece a su «Reino Medio»y, por lo tanto, debe ser cuestionado y excluido.

La escritura del Muro de Trump evidencia el código 1 del «ADN-del-muro»: nosotros los estadounidenses frente a ellos, los terroristas ilegales. Si somos capaces de descifrar y secuenciar el «ADN-del-muro», no debería ser una sorpresa enfrentarse a la prohibición musulmana, la protesta de «los judíos no nos reemplazarán», la prohibición transgénero, la burla a los discapacitados, las observaciones misóginas del presidente, la discriminación racial y la tensión antiinmigrante. Por supuesto, estas entidades deben ser excluidas del «Reino Medio» y empujadas al otro lado del Muro de Trump, de la misma manera en que hace más de dos mil años, Xiongu, Qian y Li, entre otros nómadas, fueron desterrados hacia el norte, afuera de la Gran Muralla china, debido a su «no-chinicidad» y a su falta de dignidad y adecuación con respecto al centro de la civilización y a la base del poder imperial. El «gran» Muro de Trump se encuentra con la Gran Muralla china en una ilustración y resonancia mutuas, a pesar de la distancia en tiempo y espacio. 
En sentido cultural, tanto la Gran Muralla china como el Muro de Trump son construcciones más mentales y psicológicas que arquitectónicas y físicas. Tanto el primer emperador chino, Qin Shihuang, como el presidente estadounidense del siglo XXI, Donald Trump, comparten un ego personal inflado, reflejado y magnificado en estos dos muros.

Qin Shihuang, ganador histórico, se consideraba a sí mismo como creador y centro del imperio Qin (más tarde «Reino Medio») y como gobernante de gobernantes. Su ego toma la forma, la altura y la longitud de la Gran Muralla. Por su parte, la Gran Muralla encarna e inmortaliza su egocentrismo sobre un vasto territorio y a lo largo de un patrimonio cultural inconmensurable. De este modo, el egocentrismo individual se transforma en un egocentrismo colectivo compartido e infinitamente magnificado, es decir, etnocentrismo.

Qin Shihuang nació como Ying Zheng, un príncipe del estado Qin. Después de la conquista de los Estados Guerreros y la unificación de China, se inventó un título inmortalizador -Qin Shihuang- para sí mismo, a fin de asegurar su propiedad eterna de los vastos territorios chinos, la cultura, el patrimonio y el linaje.

Al hacer un primer plano del título: «Qin» proviene de uno de los poderosos Estados Guerreros (Qin), de donde provenía el emperador. Por lo tanto, «Qin» estampa y marca la civilización china y el patrimonio cultural con su origen, su ADN y línea de sangre. «Shi» significa el principio o lo primero, resonando así la historia de la creación de Dios en el Génesis. Ying Zheng es el emperador que comienza y anticipa una larga lista de sucesores que se convertirán en el segundo, tercero, cuarto... e infinitos emperadores del Imperio Qin que aquel unificó, creó y etiquetó.

Al recién unificado pueblo chino podría importarle más un símbolo repetible que un emperador humano, pues es un símbolo que nunca muere y puede interpretar una y otra vez ese papel de cara a una identidad cultural ${ }^{4}$. Qin Shihuang actúa como ese elemento humano universal. Mientras que su línea de sucesión continúe y se simbolice en la larga línea ${ }^{5}$ de diez mil millas de la Gran Muralla, su nombre y su tierra serán heredados, abrazados, protegidos e inmortalizados por interminables generaciones futuras.

«Genéticamente», el ADN del imperio Qin ha evolucionado para ser conocido hoy como el «Reino Medio» o "Zhong Guo». «Huang» (o «Huangdi»), equivalente al emperador, el soberano o el supremo, reemplaza y diferencia todos los títulos anteriores de «rey», utilizados por los gobernantes de los Estados Guerreros. «Huang» engrandece y glorifica a Ying Zheng como el creador del imperio, la civilización, la herencia y la línea de sangre durante 10 mil generaciones y 10 mil años por identificar, honrar y celebrar. Entonces, en su significado y poder, Qin Shihuang, o el primer emperador Qin, se convierte en un sinónimo apropiado de la Gran Muralla china y del «Reino Medio». En la

4. J.M. Kopper, Building walls and jumping over them: constructions in franz kafka's 'beim bau der chinesischen mauer' (MLN, 1983), 351-365.

5. Diez mil es un número que simboliza el infinito o la perpetuidad en la cultura china y, por extensión, la inmortalidad. 
Gran Muralla, el egocentrismo de Qin Shihuang se prolonga y amplifica hacia un etnocentrismo que conlleva un modelo único chino (el Han).

El muro está incrustado en un etnocentrismo y, por lo tanto, pretende dividir la civilización y la barbarie. Al lado norte de la Gran Muralla, el pueblo nómada, Xiongnu y los mongoles, entre otras tribus, habían sido dueños de sus estepas durante generaciones; pero ahora, de repente, se encontraron con su estilo de vida cortado por la Gran $\mathrm{Mu}-$ ralla. Fueron considerados matones y bárbaros por aquellos al otro lado del Muro. Al mismo tiempo, las «fantásticas habilidades ecuestres y el virtuosismo concomitante de la gente de Xiongnu para atacar con precisión y rapidez» ${ }^{6}$, representaban una amenaza para el elogiado imperio que Qin Shihuang había creado. Para él, era un insulto tener a los Xiongnu, bárbaros del norte, como vecinos. La Muralla no solo sirvió como una fortaleza militar para mantener alejados a los bárbaros y enemigos, sino también como una línea para defender y definir una civilización y una cultura «superiores»: el Reino Medio, esto es, la China imperial en su núcleo sinocéntrico.

Hay una metamorfosis desde el egocentrismo hasta el etnocentrismo y el sinocentrismo a lo largo de la Gran Muralla y a lo largo de la historia china. Otros modos de pensar y cosmovisiones serían considerados como heréticos e inferiores y la Muralla debería bloquearlos, para que los gobernantes detrás del muro pudieran regir sin oposición y mantener el vasto reino con una cultura «pura» e instituciones «descontaminadas». Qin Shihuang estandarizó efectivamente el lenguaje, la medición y los sistemas económicos; también eliminó las 100 escuelas de pensamiento que florecieron en el período de los Estados Guerreros. Solo el legalismo fue respaldado por la dinastía Qin.

Para asegurar el dominio Qin sobre la cultura y las formas de pensamiento, libros de los Estados Guerreros y otras fuentes fueron prohibidos y quemados, los eruditos que representaban diversas voces culturales fueron enterrados vivos. De esta manera, la noción de un Reino Medio se construyó sin culturas e instituciones rivales que interfirieran con el monopolio Qin de la cultura y la mente cultural chinas. La sangre china sería «pura» en un sentido «verdadero» y «último».

Trump atrajo a votantes y partidarios con un notable desempeño de su ego, ya que ve a la sociedad estadounidense y al mundo como el escenario de su «reality show». Se proyecta a sí mismo como un ganador invencible y un magnate intocable en el negocio de los bienes raíces, un macho fuerte con bravuconadas que hablan duro, el protector y salvador de una nación frente a la incursión e infiltración de inmigrantes y musulmanes.

En el escenario de este «reality show» real, su ego se alimenta con el papel del hombre más poderoso del mundo y lo juega bajo el guion de "YO-SOY-PRIMERO», al estilo de Qin Shihuang. Su lema «los Estados Unidos primero» es marinado con el guion «YOSOY-PRIMERO». Él juega doblemente con el egocentrismo y el etnocentrismo al mismo tiempo. La promesa de campaña de Trump fue «Volver a hacer grande a los Estados Unidos». ¿Cómo? «Construye ese gran y hermoso muro» en la frontera entre EE. UU. y México para mantener alejados a los inmigrantes ilegales.

6. O. Villalon, Barbarians at the Wall (Virginia Quart Rev, 2007), 277-290. 
No hace falta decir que el Muro de Trump ha suscitado inquietudes raciales y culturales cuando surgen preguntas fundamentales como: ¿A cuál EE. UU. intenta Trump hacer grande otra vez: al multicultural y multirracial o a su "Reino Medio»? ¿A qué estadounidenses pretende proteger: a los hispano-estadounidenses, a los musulmanes estadounidenses, a los asiáticos estadounidenses, a los indios estadounidenses o solamente a los blancos? «Si crees que EE. UU. está comprometido en una batalla de vida o muerte por su identidad, en la que el pasado parece dorado y el futuro se ve, más bien, marrón, entonces, el señor Trump suena como si estuviera de tu lado.» ${ }^{7}$

Proteger el interés y la seguridad de los estadounidenses es la única frase de Trump, pero no existe una realidad estadounidense única y los intereses de EE. UU. nunca han sido una sinfonía armoniosa. La división profunda de nuestra nación abarca subdivisiones ferozmente competitivas que nos obligan a elegir a qué EE. UU. queremos pertenecer y a qué grupo deseamos adherirnos. No muy diferente a hace más de dos milenios en el otro lado de la tierra, ahora nos encontramos reviviendo a los Estados Guerreros, involucrados en guerras culturales entre ellos.

En sintonía con la globalización y la migración, la demografía en rápido cambio de EE. UU. ofrece una definición en rápida evolución del país y la población del siglo XXI. Posteriormente, los intereses y valores estadounidenses han sido sometidos a nuevas pruebas y formaciones. De una forma u otra, «los Estados Unidos deben llegar a un acuerdo con lo que significa vivir en un país con más de 40 millones de latinos/as» ${ }^{8}$, quienes hablan español, y con un número sin precedentes de inmigrantes de otros países. Los grupos de apoyo principales de Trump aún adoptan una noción obsoleta y estática de que EE. UU. es monolítico en cultura, idioma, religión y raza y que existe un «Reino Medio» que gobierna la tierra y monopoliza el poder.

Érase una vez, solo los protestantes blancos de origen noreuropeo y, por supuesto, angloparlantes, tenían derecho a la ciudadanía estadounidense y a la propiedad de sus intereses y cultura. Incluso a los propietarios originales de las tierras estadounidenses, a los indios, se les debía negar la ciudadanía en la República.

Siempre ha habido un poderoso «muro estadounidense» construido por un etnocentrismo fijo, sin importar un panorama demográfico en constante cambio. Existe una identidad estática en un etnocentrismo cultural que distingue la «civilización» de la «barbarie». Una distinción como esta se ha utilizado en todo el mundo: nuestra propia gente, históricamente, se ha volcado hacia la civilización y sus logros, mientras que la otredad es una desviación de dichos estándares ${ }^{9}$ y, por lo tanto, son inferiores. El «muro estadounidense» se ha utilizado para esta distinción y sigue bajo ese uso. Quien posea el «muro estadounidense» decidirá quién debe estar adentro y quién, afuera. Toda la historia de los EE. UU. habla sobre destruir y construir este mismo «muro estadounidense», sobre

7. Katty Kay, «Por qué los partidarios de Trump nunca lo abandonarán», Noticias de la BBC (2017), acceso: 04 de marzo de 2019, http://www.bbc.com/news/world-us-canada-41028733

8. D.A. Castillo, Anzaldúa and transnational American studies (PMLA, 2006), 260-265.

9. J. Rüsen, How to overcome ethnocentrism: approaches to a culture of recognition by history in the twentyfirst century (Hist Theory, 2004), 118-129. 
la propiedad de la cultura y la identidad, el rechazo a la ciudadanía y la confrontación de razas e instituciones, debido a ese muro. En el siglo XXI, observadores culturales y críticos han acuñado términos como política multirracial, EE. UU. multirreligioso y democracia multicultural, en un intento por rastrear una identidad cultural estadounidense en evolución. Una identidad en evolución y adaptación no sigue el límite y la delimitación de un muro, sino que aterriza en un área lo suficientemente amplia como para trazar una zona fronteriza que no permite la existencia de un «Reino Medio», sino la coexistencia de encuentros, intersecciones y confluencias de «estados guerreros».

En el último medio siglo, el «muro estadounidense» ha instalado un mayor número de puertas y ventanas, abiertas a paisajes y direcciones previamente cerradas y bloqueadas. Sin embargo, el elemento definitorio del «americanismo» todavía es limitado y moldeado por el muro del grupo del «Reino Medio». Este grupo aún se mantiene firme y domina la idea de que la nación y la cultura estadounidenses pertenecen exclusivamente a un grupo, un credo y una raza. Cuando se percibe una amenaza a esta "pureza» y «unidad», es decir, a los estadounidenses blancos, protestantes de origen noreuropeo y hablantes de inglés, se cierran las puertas y ventanas del «muro de los Estados Unidos». Una construcción mental como esta apela a «un segmento de la población blanca más vieja que teme que la cultura nacional con la que crecieron se desvanezca» ${ }^{10}$.

La mentalidad-del-muro también proporciona una base comprensible e identificable para una masa de la clase trabajadora, no especialmente educada ni con conocimiento actual sobre un mundo global complejo en el siglo XXI. Así, el Muro de Trump se convierte en un fenómeno cultural, compartido y colectivo, que personifica un etnocentrismo del siglo XXI en los EE. UU. trumpianos.

La cerca de hierro en la frontera es un gesto simbólico que tiene sentido para personas motivadas por prejuicios contra otra cultura ${ }^{11}$. Tierra fértil para que crezcan el miedo, el aislamiento y para crear distancia y fanatismo entre culturas y personas, el etnocentrismo trumpiano se convierte en una base muy deseada para el muro, tanto en las mentes estadounidenses como en la frontera de EE. UU. y México. El Muro de Trump es una demarcación geográfica, pero más aún una demarcación de razas, culturas, idiomas y cosmovisiones. Reclama y protege la propiedad de la cultura y la identidad de ciertos estadounidenses y niega la propiedad de las mismas cosas a otros.

\section{Conclusión}

La historia ha demostrado que, a pesar de todo el esfuerzo épico de defensa y protección, la Gran Muralla china no era invulnerable; de hecho, era porosa, tan permeable y penetrable que los mismos «bárbaros», los mongoles (Kublai Khan) que pretendía mantener afuera, gobernaron el Reino Medio desde 1271 hasta 1368 en el esplendor de la gran dinastía Yuan. Mientras tanto, la muralla ha sido reutilizada y desafiada desde

10 F. Zakaria, «Why Trump won», cnn.com, acceso: 04 de marzo de 2019, http://www.cnn.com/2017/07/31/ opinions/why-trump-won-zakaria/index.html

11 J.A. Bustamante, Demystifying the United States-Mexico Border (J Am Hist, 1992), 485-490. 
adentro; su cerrazón y aislamiento han contradicho repetidamente la formación y el desarrollo de una nación y una civilización.

La Ruta de la Seda fue formulada en la dinastía Han y reabierta por el Imperio Tang en 643, permaneciendo abierta durante las siguientes cuatro décadas. La ruta terrestre de Eurasia funcionó como un conducto comercial de dos vías entre China y Occidente, tejiendo una red gigante de comercio y fusión de nuevas ideas, tecnologías y expresiones artísticas. Se intersecaron diferentes religiones, idiomas y formas de vida, lo cual era impedido, precisamente, por la Gran Muralla.

Si la Ruta de la Seda «rompió» la Gran Muralla en tierra, Zheng He (1371-1435), gran navegante de la Dinastía Ming, hizo otro agujero «irreparable» en la ella, al establecer una ruta marítima para llegar a lo que estaba más allá de la Gran Muralla. Irónicamente, la dinastía Ming de Zheng He se ha conocido por la renovación y continuación de la Gran Muralla. Antes de la llegada de Cristóbal Colón al Nuevo Mundo, Zheng He realizó siete viajes entre 1405-1433 al sudeste, sur y oeste de Asia, y el este de África llevó al Imperio Ming / la China imperial a aguas inexploradas, dando a conocer la Gran Muralla en un mundo desconocido. Además, quizás más irónicamente, los poros en la muralla estaban tan abiertos y eran tan anchos que permitieron a los ciudadanos del siglo XXI penetrar la muralla china en el tiempo y en el espacio, a través de continentes, por un periodo de dos mil años ${ }^{12}$.

¿Logrará el Muro de Trump lo que la Gran Muralla China no consiguió para disuadir y detener a quienes lo cruzan? La respuesta está oculta en el ADN-del-muro que ambos comparten. Según lo analizado por Angelucci ${ }^{13}$, los controles fronterizos son endógenos y están correlacionados con las fuerzas del otro lado del muro. Ambas murallas se erigen para servir al etnocentrismo en un momento en que la «pureza» de sangre y la «homogeneidad» del suelo se toman como identidad cultural y nacional. Ambos etnocentrismos se derivan de los egos indefensos de dos individuos y se transforman en un egocentrismo magnificado y colectivo. Ambas pretenden excluir en lugar de incluir. Ambas envían un mensaje simbólico y cultural con una estructura física poderosa. Ambas tienen un «Reino Medio» por defender y proteger y hacen desaparecer la gran distancia, en tiempo y espacio, entre ellas.

Al permitirse cruzar de un lado a otro entre las dos paredes, el ADN-del-muro revela una visión de mundo fosilizada y basada en el miedo, incrustada en un etnocentrismo atemporal. El «Gran» muro de Trump es una negación de la identidad cultural estadounidense del siglo XXI, en proceso de creación; es un intento de revivir el poder del «Reino Medio» de una sola raza, un solo credo y una sola cultura. El «Gran» Muro de Trump tiene la intención de bloquear a quienes cruzan las fronteras físicas, pero no podrá detener el flujo bidireccional de las energías culturales o los fuertes lazos históricos. El Muro de Trump nunca detendrá la formación continua de una identidad cultural estadounidense del siglo XXI.

12. Grossman (2010) también atestigua la ilusión del sentido protector de la Gran Muralla china desde la perspectiva del comercio y el mercado de valores. Índices entrecruzados y fondos mutuos son un rompimiento comprobado de la muralla.

13. M. Angelucci, US border enforcement and the net flow of mexican illegal migration (Econ Dev Cult Change, 2012), 311-357. 


\section{ABSTRACT}

\section{Crossing between the Great Wall of China and the "Great" Trump Wall}

Can a border wall really deter invaders and crossers alike, while defending, unifying, and maintaining the "purity" of the culture that it encircles? The first Chinese emperor Qin Shihuang (259$210 \mathrm{BC}$ ) and his successors in the following dynasties tried to achieve the purpose; the Great Wall of China testifies timelessly to such epic efforts. Have the Chinese rulers succeeded? The question has become increasingly daunting and unanswerable as history unfolds and evolves. Ironically, over more than two millennia, the piecemeal erection of the Great Wall has indeed sequenced a 'wall-DNA' in a cultural blueprint. Fast forwarding to the $21^{\text {st }}$ century America, we find ourselves asking the same questions when President Trump vows to build a "great, great" wall, physical and impenetrable on the US-Mexico border. The Trump Wall is designed to stop Mexican illegal immigrants entering the US so that Americans' interests will be protected, English language will not be "contaminated", and American values will not be challenged. The Trump wall sets out to delineate what America is and thus attempts to "make America great again". In an intercultural engagement, this article decodes a wall-DNA in American culture, argues that the Trump wall is more of a mental construct than a physical one, and calls for a redefinition of a $21^{\text {st }}$ century American cultural identity, in front of the Trump Wall.

Key words: Trump Wall, Great Wall of China, border, Mexico, inmmigration.

\section{RÉSUMÉ}

\section{À travers la Grande Muraille de Chine et le «grand» mur de Trump}

Un mur marquant frontière, peut-il décourager les envahisseurs ainsi que ceux qui le traversent, et en même temps défendre, harmoniser et maintenir la "pureté» de la culture qu'il enferme? Le premier empereur chinois Qui Shihuang (259-210 avant J-C) et ses prédécesseurs dans les dynasties suivantes ont essayé d'atteindre ce but ; la Grande Muraille de Chine témoigne éternellement de ces efforts épiques. Est-ce que les dirigeants chinois ont eu du succès? Cette question est de plus en plus décevante et incontestable au fur et à mesure que l'histoire se développe et évolue. Ironiquement, pendant plus de deux mille ans, la construction fragmentée de la Grande Muraille a séquencé un «ADN du mur» qui est resté enregistré comme une empreinte culturelle. Dans la progression assez rapide vers les États-Unis du XXI siècle, ces mêmes questions se sont posées lorsque le président Trump promet construire un mur «grand, grand» physique et impénétrable le long de la frontière entre les États-Unis et le Mexique. Le mur de Trump a été conçu pour arrêter les immigrants illégaux mexicains qui entrent aux États-Unis afin de protéger les intérêts américains, d'éviter la «pollution» de la langue anglaise et que ses valeurs ne soient pas mises en question. Ce mur s'établit pour montrer ce que sont les États-Unis et essaie de refaire de l'Amérique un grand pays. Sous un engagement interculturel cet article décode «l'ADN du mur» dans la culture américaine en arguant que le mur de Trump n'est qu'une construction plus mentale que physique en invitant à redéfinir l'identité étatsunienne du XXI siècle à ce mur.

Mots-clés: Mur de Trump, Grande Muraille de Chine, frontière, Mexique, immigration.

\section{Bibliografía}

Angelucci, M. US border enforcement and the net flow of mexican illegal migration. Econ Dev Cult Change, 2012.

Bustamante, J.A. Demystifying the United States-Mexico Border. J Am Hist, 1992.

Castillo, D.A. Anzaldúa and transnational American studies. PMLA, 2006. 
Grossman, E. A new Great Wall. Foreign Policy, 2010.

Katty Kay. «Por qué los partidarios de Trump nunca lo abandonarán». Noticias de la BBC. Acceso: 04 de marzo de 2019. http://www.bbc.com/news/world-us-canada-41028733

Kopper, J.M. Building walls and jumping over them: constructions in franz kafka's 'beim bau der chinesischen mauer'. MLN, 1983.

Lattimore, O. Origins of the Great Wall of China: a frontier concept in theory and practice. Geogr Rev, 1937.

Villalon, O. Barbarians at the Wall. Virginia Quart Rev, 2007.

Rüsen, J. How to overcome ethnocentrism: approaches to a culture of recognition by history in the twenty-first century. Hist Theory, 2004.

Zakaria, F. «Why Trump won». Acceso: 04 de marzo de 2019. http://www.cnn.com/2017/07/31/opinions/whytrump-won-zakaria/index.html 